\title{
BMJ Open Effectiveness of the 'Back-to-Sleep' campaigns among healthcare professionals in the past 20 years: a systematic review
}

\author{
Federico de Luca, ${ }^{1}$ Andrew Hinde ${ }^{2}$
}

To cite: de Luca F, Hinde A. Effectiveness of the 'Back-toSleep' campaigns among healthcare professionals in the past 20 years: a systematic review. BMJ Open 2016:6:e011435. doi:10.1136/bmjopen-2016011435

- Prepublication history for this paper is available online. To view these files please visit the journal online (http://dx.doi.org/10.1136/ bmjopen-2016-011435).

Received 25 February 2016 Revised 28 June 2016 Accepted 20 July 2016

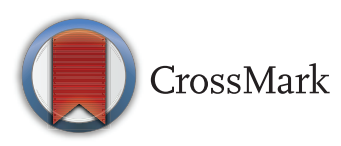

${ }^{1}$ School of Social Sciences: Social Statistics \& Demography, University of Southampton, Southampton, UK

${ }^{2}$ Southampton Statistical Sciences Research Institute, University of Southampton, Southampton, UK

Correspondence to Dr Federico de Luca; F.Deluca@soton.ac.uk

\section{ABSTRACT}

Objectives: From the late 1980s 'Back-to-Sleep' (BTS) campaigns were run in most developed countries to increase awareness of the supine position's protective effect against sleep-related infant deaths. Once the media awareness-raising action associated with these campaigns ended, healthcare professionals' role became crucial. The goal of this paper is to determine if healthcare professionals' knowledge and parent advice consistent with evidence-based infant sleep recommendations have changed over the past 20 years.

Setting: All studies investigating healthcare professionals' knowledge and/or advice to parents were included in a systematic review. The search was performed in PubMed and in MEDLINE, and 21 studies were identified.

Results: The correctness of healthcare professionals' knowledge and parent advice about the supine sleeping position increased over the past 20 years. However, the percentage of those aware that parents should avoid putting their babies to sleep in a prone position is decreasing over time: from about $97 \%$ in the 1990 s to about $90 \%$ at the end of the 2000s.

Conclusions: The effectiveness of the BTS campaigns in publicising the benefits of the supine position is confirmed by this paper. More and more healthcare professionals know that it is the best position to reduce the risk of sleep-related deaths and they recommend it exclusively. However, the decrease in the knowledge about non-prone positions suggests that the campaigns may not have focused enough on the dangers of the prone position.

\section{INTRODUCTION}

Sleep-related infant deaths (also known as 'cot deaths' or 'crib deaths') are still an important cause of death of healthy born infants in developed countries. ${ }^{1}{ }^{2}$ Most of these deaths are diagnosed as Sudden Infant Death Syndrome (SIDS), while a minority involve accidental asphyxia. ${ }^{3}$ SIDS may be defined as "the sudden unexpected death of

\section{Strengths and limitations of this study}

- This study generates the first comprehensive analysis of the effect of the 'Back-to-Sleep' campaigns on healthcare professionals' knowledge and parent advice about infants sleeping positions.

- All the results are based on published data.

- The number of studies is relatively small, as this field has not yet been extensively explored. This implies that the results of the paper may be less accurate, although it may also limit the potential impact of any publication bias on the analysis.

- While the trend was largely constructed on the basis of US studies, the most recent data belong only to other countries, and this may imply problems in terms of comparability.

an infant $<1$ year of age, with onset of the fatal episode apparently occurring during sleep, which remains unexplained after a thorough investigation, including performance of a complete autopsy and review of the circumstances of death and the clinical history'. ${ }^{4}$ The incidence of SIDS rises to a peak between ages 1 and 4 months and then decreases. About $90 \%$ of SIDS deaths happen in the first 6 months of life; almost two-thirds of the cases happen at night; most cases happen in winter; and boys are more likely to die than girls (ratio 60:40). ${ }^{5}$ More recently, epidemiologists have started using the broader term Sudden Unexpected Death in Infancy (SUDI) which includes SIDS and other sleep-related deaths. ${ }^{6}$ In what follows, we use SUDI or 'sleep-related infant deaths' to refer to this broader categorisation, but retain the term SIDS when reporting on research which itself used that term.

Since the 1980s there have been many campaigns and interventions in developed countries aimed at reducing the incidence of sleep-related infant deaths. ${ }^{7}$ Before the first campaigns, sleeping position was the 
strongest risk factor for which it was possible to intervene to reduce the risk of SUDI. The supine position is the safest position. Compared with the supine, the prone position has 2.3-13.1 times the risk of death from SIDS, and the lateral position 2.0 times the risk $(95 \%$ CI 1.2 to 3.4) ${ }^{8-12}$ Overall, the dangers of the prone and lateral positions can be considered very similar, especially if we account for the population-attributable risk. ${ }^{12} 13$ In 1985, Davies discovered that in Hong Kong, where the common habit was to put infants to sleep in a supine position, SIDS was very rare. ${ }^{14}$ On the contrary in the USA, where the SIDS rate was much higher, most infants were placed in their bed prone until $1992 .{ }^{15} \mathrm{It}$ was believed that the prone position granted benefits (such as a lower likelihood of aspiration and a lower gastro-oesophageal reflux). ${ }^{15} 16$ Following Davies's findings, many epidemiological studies in the 1980s and 1990s showed a lower incidence of SIDS in those infants who slept supine. Guntheroth and Spiers ${ }^{17}$ pooled the evidence collected up to 1992, whence in countries such as the Netherlands, the UK, Australia and New Zealand public health campaign recommendations regarding avoidance of the prone position began to be given to parents between 1987 and 1991. In 1992 the American Academy of Pediatrics (AAP) published recommendations for reducing the risk of SIDS, strongly discouraging all those in charge of newborns from putting them to sleep prone. ${ }^{15}$ In 2005 an updated version of the AAP guidelines recommended exclusively the supine sleeping position, a recommendation which was confirmed in 2011. ${ }^{18} 19$ The campaigns run in developed countries, which we shall call 'Back-to-Sleep' (BTS) campaigns, aimed to raise awareness of the supine position's effect in reducing the risk of SIDS. Owing to the action of these campaigns, the major risk factor for SIDS is nowadays considered to be smoking (both during pregnancy and in the infant's environment). ${ }^{19}$

The objective of this paper is to evaluate if healthcare professionals' knowledge and advice to parents about infant sleeping positions have changed over the past 20 years and to what extent they are aligned with public health recommendations. In order to achieve this, we will systematically review the findings of studies investigating the knowledge that healthcare professionals have about sleeping positions and the advice given by healthcare professionals to parents. Both knowledge and parent advice will be analysed. Since most studies have been conducted in the USA, special attention will be given to this case.

\section{METHODS}

Studies were sought in the PubMed and MEDLINE databases, using groups of keywords including 'SIDS', 'knowledge', 'recommendation(s)', 'advice', 'back to sleep', 'safe sleep', 'healthcare professionals', 'doctors', 'nurses', 'physicians', 'paediatricians', 'supine position', 'non-prone position', 'prone position', 'prevention' and 'reducing'. Eligibility was assessed without reference to results, authors or journals, and when the required data could not be extracted, the original authors were contacted. Experts in the field were consulted to identify other relevant studies. To ensure accuracy, the two authors independently assessed eligibility of all the studies considered. Once the studies of interest were identified, both authors extracted data independently and the results were compared. No differences were found between the two reviewers' outcomes. When it was necessary to pool together the results of several surveys carried out the same year, calculations of annual percentages were made using absolute frequencies.

A study was included if it investigated healthcare professionals' knowledge and/or parent advice about infant sleeping positions and, as we focused on the 20-year period post-BTS campaigns (which ends approximately in 2012), if it was published before 2013. All studies meeting these criteria were considered, regardless of the reference time of their survey(s) and of their publication year. Data regarding both the supine position alone and the non-prone positions were extracted. The eligible studies involved the family/general physicians, paediatricians, obstetrician-gynaecologists, other physicians, midwives, head nurses, neonatal intensive care unit nurses, nursery nurses and other nurses. All were published in international peer-reviewed journals in English. A search of the databases was also performed in French, Italian and Spanish, but no eligible study published in these languages was found. Figure 1 provides a flow chart illustrating the selection of studies. The search was first undertaken in January 2012 and updated in February 2013.

From each study we retrieved, where possible, absolute frequencies and the respective percentages relating to: (1) awareness of supine position being best (2) recommending supine position (3) awareness of non-prone position lowering risk and (4) recommending nonprone position. It was assumed that the following definitions described the same concept: 'healthcare professionals aware of the latest AAP recommendations for back and side sleeping position', 'healthcare professionals aware that term infants should be placed on their back to sleep', 'healthcare professionals aware that the supine position is a protective factor against SIDS' and 'healthcare professionals aware that the supine position is associated with the lowest risk of SIDS'. Some studies gave details about supine and non-supine positions, while others broke them down for all possible positions. With the latter it was possible to infer both the supine and the non-prone information, while with the former items (3) and (4) above could not be retrieved. We only extracted figures that we were sure actually measured the outcomes we sought. We excluded other statistics, such as the proportion of newborns actually put to sleep in the supine position in the hospitals where surveys were conducted, as we were unsure that these reflected the personal knowledge or opinions of the respondents. 


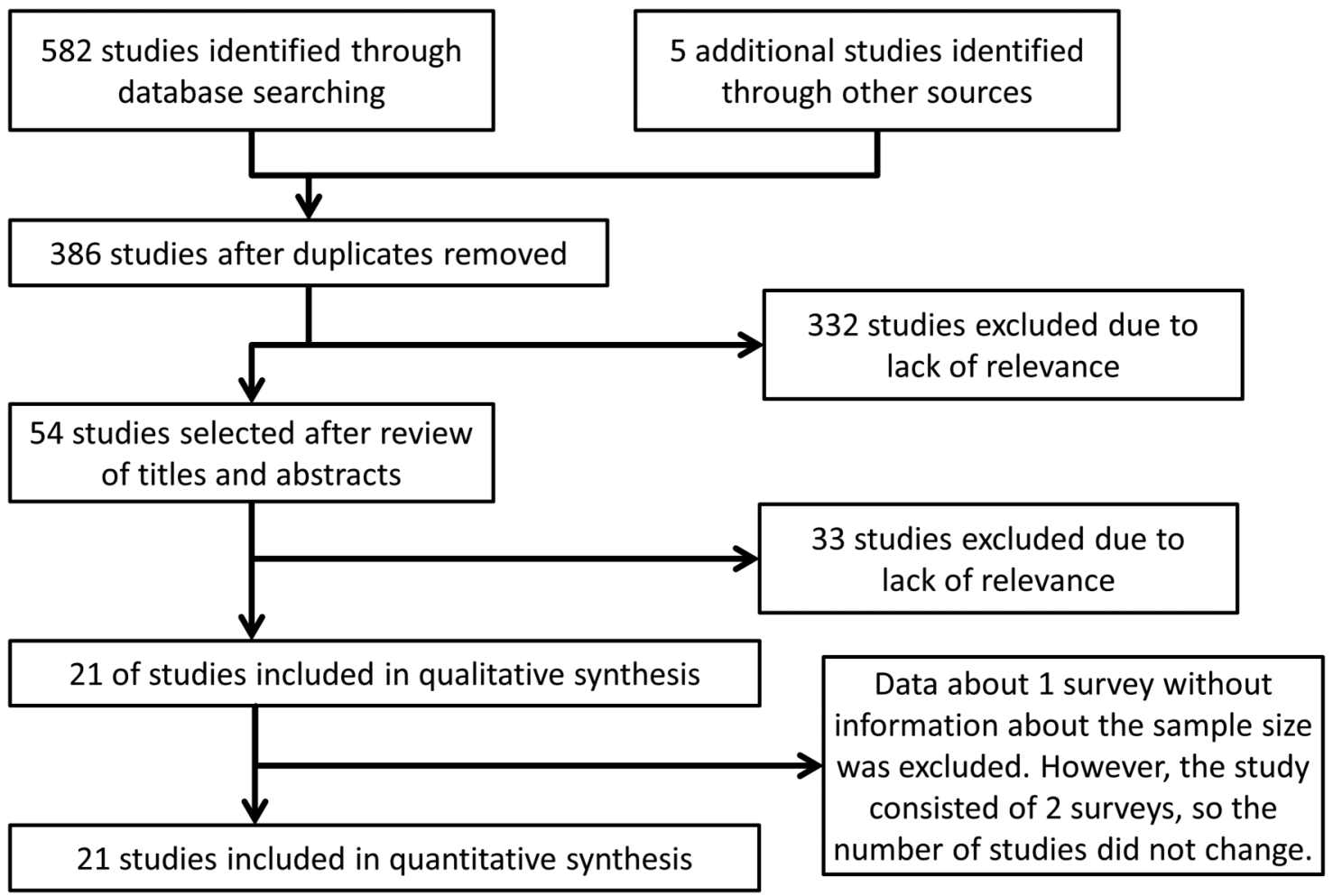

Figure 1 Flow chart of systematic review and study selection.

We summarised how these four percentages have changed over the past 20 years. The results of each study were attributed to the year(s) when the respective survey(s) were conducted, without considering the year of publication of the study. If the year of a survey was not available (2 cases), we hypothesised a 2-year lag between the year when the survey was carried out and the date when the study was accepted for publication. If more than one study related to the same year, their average was taken and weighted according to their sample sizes. If a study presented data referring to periods both before and after a training course, only those preceding the training course were considered. Data collected over periods of more than 1 year were assumed to be valid for all relevant years. We performed weighted regressions where the yearly weights were determined by the number of healthcare professionals surveyed in order to show trends. Given the limited and somehow heterogeneous nature of the studies that were considered, we only present the results of the regression in the figures for an illustrative purpose and we prefer not to focus our discussion on the interpretation of the regressions' results.

\section{RESULTS}

Of the 21 selected studies, the earliest was in 1992 and the most recent in 2009. These 21 studies described 25 different surveys and 24 different published papers (table 1). The data for the survey without sample size information were excluded from the analysis. However, that survey belonged to a study consisting of two surveys, so the overall number of considered studies did not change. Most of the surveys (19) were carried out in the USA, three in Australia, one in Italy and one in Turkey. For this reason, the results are presented with reference to the USA, but the data relating to non-US surveys will also be included in the graphs. The average sample size of the studies included was 512 respondents (minimum=27, maximum $=5861$ ) and the average response rate was $68.4 \%$ (minimum $=23.5 \%$, maximum $=100 \%)$. In order to give clear and exhaustive information to readers, in table 1 we also present response rate and survey mode of all surveys. However, these details are not discussed in the paper.

\section{Healthcare professionals' knowledge on safe sleep}

The percentage of healthcare professionals who are aware that the supine position is the best for reducing the risk of SIDS has increased in the USA over the past 20 years, while the percentage of healthcare professionals who are aware that any non-prone position would be better than the prone position seems to have been decreasing over the past 20 years (figure 2). The results of non-US studies seem to be comparable to those of the USA, especially concerning knowledge of the dangers of the prone position.

The respondents in the studies reviewed came from a variety of healthcare professions. A small subset of the studies presented in table 1 (three US studies and one non-US study) also included data specific to particular groups. In all cases, paediatricians' knowledge of the risks of different sleep positions was more than that of other healthcare professionals (table 2). 
Table 1 Main characteristics of all the surveys of interest (some studies involve more than one survey, NA, not available)

\begin{tabular}{|c|c|c|c|c|c|c|c|c|c|c|}
\hline \multirow[b]{2}{*}{ Area } & \multirow[b]{2}{*}{ Year of reference } & \multirow[b]{2}{*}{ Healthcare professionals } & \multirow[b]{2}{*}{ Sample size } & \multirow[b]{2}{*}{ Response rate (\%) } & \multirow[b]{2}{*}{ Survey mode } & \multicolumn{2}{|c|}{ Knowledge (\%) } & \multicolumn{2}{|c|}{ Parent advice (\%) } & \multirow[b]{2}{*}{ Reference } \\
\hline & & & & & & Supine & Non-prone & Supine & Non-prone & \\
\hline USA & 1992 & Paed, FamPhys, Phys, Nurses & 630 & 73.3 & Telephone & & & & 54.6 & 20 \\
\hline USA & 1992 & Head Nurses & 79 & 100 & Telephone & & 92.4 & 0 & 67.1 & 21 \\
\hline USA & 1992 & Paed, FamPhys & 121 & 81.2 & Mail & & & $4.0^{*}$ & $24.0^{\star}$ & 22 \\
\hline USA & 1993 & Paed, FamPhys & 121 & 81.2 & Mail & & 98.3 & $16.0^{\star}$ & $87.0^{\star}$ & 22 \\
\hline USA & $1993 \dagger$ & Paed & NA & NA & NA & & & 77.0 & & 23 \\
\hline USA & 1995 & FamPhys & 209 & 69.7 & Mail & & & 60.8 & & 23 \\
\hline USA & $1995-1996$ & Phys & 27 & 100 & Paper/pencil & & & & 84 & 24 \\
\hline USA & 1996 & Nurses & 103 & 47.0 & Paper/pencil & & 97.1 & & & 25 \\
\hline USA & 1997 & Paed & 34 & 81.0 & NA & & & 35.3 & 100 & 26 \\
\hline USA & 1998 & Head Nurses & 94 & 100 & Mail & & & & 90.5 & 27 \\
\hline USA & 1999 & Head Nurses & 75 & 100 & Telephone & & 100 & 26.7 & 100 & 21 \\
\hline USA & 1999 & Paed, FamPhys, ObsGyn & 835 & 22.5 & Mail & 52.6 & & & & 28 \\
\hline USA & 2000 & Nurses & 528 & 31.6 & Mail & 44.0 & 96.0 & & 82.0 & 29 \\
\hline USA & 2000 & Nursery Nurses & 96 & NA & NA & 71.6 & & 33.7 & 98.9 & 30 \\
\hline USA & $2002 / 2004$ & Paed, FamPhys, ObsGyn & 214 & 23.5 & Mail & 72.3 & & & & 31 \\
\hline USA & $2003 / 2004$ & NICU Nurses & 252 & 49.0 & Mail & & & 52.0 & 98.8 & 32 \\
\hline USA & $2004 / 2005$ & Nursery Nurses & 530 & NA & NA & & & 55.1 & 97.9 & 33 \\
\hline USA & $2004 / 2007$ & Nurses & 395 & 62.2 & NA & 84.8 & & & & 34 \\
\hline USA & 2005 & Paed, FamPhys & 783 & 26.1 & Mail & 77.5 & 95.8 & 69.6 & 96.7 & 35 \\
\hline USA & $2007 / 2008$ & NICU Nurses & 430 & 39.8 & NA & 60.5 & 87.0 & 84.0 & & 36 \\
\hline Australia & 2001 & Nurses, Midw & 36 & 100 & Paper/pencil & 91.7 & 100 & 77.8 & 100 & 3738 \\
\hline Australia & 2001/2002 & Nurses, Midw & 959 & 81.1 & Mail & 70.9 & 99.3 & 61.2 & 99.5 & 39 \\
\hline Australia & $2006 / 2007$ & Nurses, Midw & 220 & 59.0 & Mail & 82.0 & & 78.0 & 100 & 40 \\
\hline Other & $2008 \dagger$ & $\begin{array}{l}\text { Paed, FamPhys, Phys, Nurses, } \\
\text { Midw }\end{array}$ & 174 & 90.6 & Face to face & 16.7 & 89.7 & 10.8 & 67.0 & 41 \\
\hline Other & $2008 / 2009$ & $\begin{array}{l}\text { Paed, ObsGyn, Phys, Nurses, } \\
\text { Midw }\end{array}$ & 4533 & NA & Paper/pencil & 89.6 & & 61.2 & 82.4 & 4243 \\
\hline
\end{tabular}

${ }^{*}$ Estimated by eye from a graph in the original article.

Estimated by supposing a 2 years lag between when the survey was carried out and when it was accepted for publication.

Paed, paediatricians; FamPhys, family physicians; Midw, midwives; NICU, neonatal intensive care unit; ObsGyn, obstetricians-gynecologists; Phys, other physicians. 


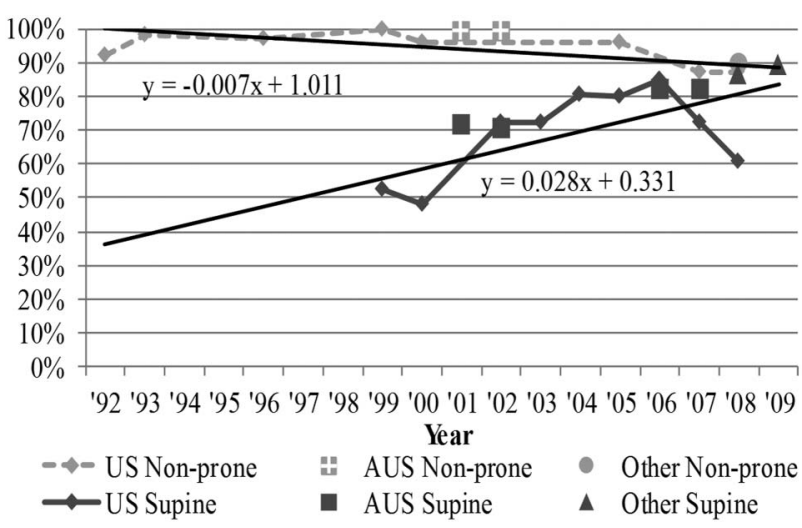

Figure 2 Percentage of healthcare professionals aware that the supine (or any non-prone) sleeping position is the most effective in reducing the risk of SIDS (for USA, Australia, and Other countries). SIDS, Sudden Infant Death Syndrome.

\section{Healthcare professionals' advice to parents on safe sleep} In figure 3 we observe an increasing trend in the percentage of healthcare professionals recommending both exclusively the supine position and a non-prone one. In the case of the non-prone position, this result contradicts the trend in reported knowledge described in figure 2, although we have no data on parent advice about the non-prone position for the years after 2005, when awareness of the particular dangers of the prone position is at its lowest. Figure 3 also suggests that the Australian results seem to be better than the American ones, while those belonging to other countries, which are also the most recent, reveal that in their case, advice to parents from healthcare professionals is less beneficial to infants than in the USA. In the only study that compared the parent advice of different types of healthcare professionals, $74 \%$ of paediatricians but only $62 \%$ of other healthcare professionals would recommend the supine position. ${ }^{35}$

\section{DISCUSSION}

Current sleep-related infant death rates are much lower than those registered before the BTS campaigns started to be implemented. In table 3 we show how SIDS rates changed over the past 20 years. For some countries,

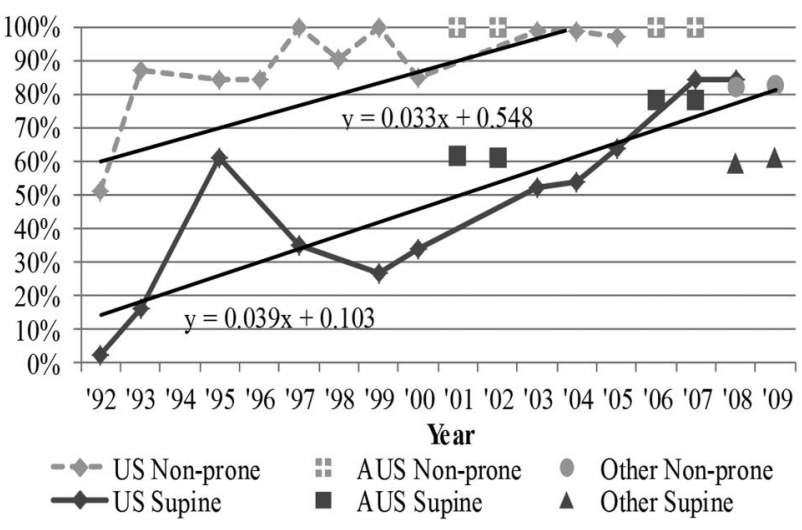

Figure 3 Percentage of healthcare professionals recommending parents of newborns the supine (or any non-prone) sleeping position (for USA, Australia and Other countries).

SIDS rates were derived by combing official statistics from different sources.

In 2005, Raydo and Reu-Donlon ${ }^{56}$ focused on the importance of healthcare professionals for transmitting the correct recommendations to parents and reviewed the available literature regarding professionals' attitudes and beliefs about infant sleep positioning. This study generates the first comprehensive analysis of the effect of the BTS campaigns on healthcare professionals' knowledge and advice to parents about infants sleeping positions. All the results are based on published data.

\section{Healthcare professionals' knowledge on safe sleep}

The percentages of healthcare professionals aware that the supine position is best for reducing the risk of SUDI and recommending parents of newborns to use the supine position exclusively have been increasing over the past 20 years in parallel with the increasing number and extent of BTS campaigns, mainly focused in getting the message that 'back is best' through to the population. This suggests that the BTS message reached healthcare professionals as well as parents of newborns. A surprising result of this analysis was that the percentage of healthcare professionals believing that any non-prone position implied a lower risk of SUDI has decreased over the past 20 years. This could be interpreted as suggesting

Table 2 Comparison between different healthcare professionals in terms of knowledge that the supine position is the safest for reducing the risk of SIDS

\begin{tabular}{|c|c|c|c|c|c|c|c|}
\hline Area & Year & $\begin{array}{l}\text { Paediatricians } \\
(\%)\end{array}$ & $\begin{array}{l}\text { Family } \\
\text { physicians (\%) }\end{array}$ & $\begin{array}{l}\text { Nurses and } \\
\text { healthcare assistants } \\
(\%)\end{array}$ & $\begin{array}{l}\text { Obstetricians } \\
(\%)\end{array}$ & $\begin{array}{l}\text { Other } \\
\text { roles (\%) }\end{array}$ & Reference \\
\hline USA & 1992 & 64 & 51 & & & 48 & 20 \\
\hline USA & 1999 & 67 & & & & 37 & 28 \\
\hline USA & 2005 & 82 & 70 & & & & 35 \\
\hline Other & $\begin{array}{l}2008 / \\
2009\end{array}$ & 97 & & 88 & 89 & 79 & 4243 \\
\hline
\end{tabular}


Table 3 SIDS rate in 1987 (per 1000 healthy born infants), the year when the BTS campaigns began, and the most recent SIDS rate (with reference year) for the 12 most populated developed countries

\begin{tabular}{|c|c|c|c|}
\hline Country & SIDS rate in 1987 & $\begin{array}{l}\text { Year when the BTS campaigns } \\
\text { began }\end{array}$ & $\begin{array}{l}\text { Most recent SIDS rate and year } \\
\text { of reference }\end{array}$ \\
\hline Australia & $2.49^{44}$ & $1991^{45}$ & $0.20_{(2013)}^{46}$ \\
\hline Canada & $1.06^{44}$ & $1993^{45}$ & $0.19_{(2011)}^{47}$ \\
\hline France & $1.85^{44}$ & $1994^{45}$ & $0.25(2012){ }^{48}$ \\
\hline Germany & $1.64^{44}$ & $1991^{45}$ & $0.22(2013) 49$ \\
\hline Italy & $0.11^{\star} \dagger$ & $2008^{50}$ & $0.03_{(2012)} \dagger$ \\
\hline Japan & $0.10^{44}$ & $1998^{45}$ & $0.12(2013)^{51}$ \\
\hline Netherlands & $0.91^{44}$ & $1987^{45}$ & $0.06{ }_{(2014)}^{1}$ \\
\hline Poland & $0.26^{\star} \dagger$ & Not available & $0.13_{(2012)} \dagger$ \\
\hline South Korea & Not available & Not available & $0.20(2014) 5$ \\
\hline Spain & $0.30 * \dagger$ & $2000^{53}$ & $0.11_{(2012)} \dagger$ \\
\hline UK & $2.40^{44}$ & $1991^{54}$ & $0.24_{(2012)}^{55}$ \\
\hline USA & $1.37^{44}$ & $1994^{45}$ & $0.87_{(2013)^{2}}$ \\
\hline
\end{tabular}

that the BTS campaigns concentrated all their energies in publicising the benefits of the supine position without sufficiently stressing the dangers of the prone position. As a consequence, while awareness that the supine position is the best for reducing the risk of SUDI increased over time fewer people could be aware of the dangers of the prone position.

If we briefly look at the differences between professional figures, paediatricians' knowledge on this topic seems to be more than that of others. This information may be useful for policymakers of countries where paediatricians are expected to play an active and daily role in delivering the message for reducing the risk of SUDI to parents. In other countries, though, the benefits could be limited, as different professionals may be in charge of delivering advice to parents. In the UK, for example, women whose pregnancies follow a normal development will probably never meet paediatricians or obstetrician-gynaecologists. Instead, they would have regular contacts with midwifes, health visitors and, most likely, general practitioners. When knowledge is considered, non-US studies show results similar to the USA ones, if not better. In 1987 Australia had the highest SIDS rate for any large country (table 2) but its SIDS rate has since converged with those of other countries, and is now lower than that of the USA. Our results show that in relation to both awareness and parent advice, Australia has been performing better than the USA, suggesting that there may be an association between the quality of the information possessed by healthcare professionals and the reduction in the SIDS rate.

\section{Healthcare professionals' advice to parents on safe sleep}

Once the campaigns are over healthcare professionals are the most important conduit through whom the message is transmitted to parents. It could be argued that, as far as parents of newborns are concerned, what healthcare professionals recommend is more important than what they claim to know. By 2004, almost $100 \%$ of healthcare professionals were recommending a non-prone position.

The advising of parents is a complex topic. In the past, it emerged has that some healthcare professionals perceive the official guidelines as potentially harmful for newborns. This is the case, for example, of those professionals who do not recommend the supine position for fear of regurgitation and aspiration. ${ }^{57}$ However, when giving advice to parents, healthcare professionals have to (or should) comply with the public health recommendations of their country, regardless of their knowledge, opinions and beliefs. This is not necessarily true when knowledge is considered, as each professional can undergo further training or further reading from the literature as he/she deems it necessary. The fact that the percentages of those recommending both exclusively the supine position and a non-prone one have increased over the past 20 years is reassuring. In the second case, particularly, this contradicts what was observed for the trend in knowledge, suggesting that healthcare professionals actually leave aside their personal opinions, fears and beliefs when giving parents advice.

Although the impact of the BTS campaigns cannot be established with this kind of data, it seems legitimate to suppose that these campaigns played an important role in the awareness-raising process. The last two non-US studies included in this review are from Italy and Turkey: in Italy the first national BTS campaign was carried out only in 2008, and in Turkey it was not possible to determine whether a national BTS campaign was ever implemented. While this does not mean that healthcare professionals in these countries did not benefit from 
BTS campaigns carried out in other countries (and reinforced by publications in the scientific literature), it shows a limited level of attention given by local policymakers to this issue over the past 20 years. This might explain why their performance in terms of advice to parents seemed to be below that of the USA and Australia.

The analysis reported in this paper has limitations: the number of studies is relatively small, as this field has not yet been extensively explored. This implies that the results of the paper may be less accurate, although it may also limit the potential impact of any publication bias on the analysis. While the trend was largely constructed on the basis of US studies, the most recent data are from other countries, and this may imply that there may be problems in terms of comparability. It is also possible that we could have found more studies to include in the analysis if we had extended the search to more databases other than PubMed and MEDLINE.

The reliability of the trend lines may be influenced by the estimates that were made where the year of the surveys was unknown and by the hypothesis that, in case of surveys carried out over more than 1 year, their data was assumed to relate to all relevant years. The quality of the information in the studies reviewed may vary according to the mode of the survey (face-to-face, telephone, mail, etc). Unfortunately, there are insufficient studies for us to be able to stratify on the basis of survey mode and some studies did not indicate how the survey was conducted (table 1).

\section{CONCLUSION}

The BTS campaigns and the advice given by authorities such as the AAP have been effective in helping raising awareness among healthcare professionals of the relative risks of sleep-related infant deaths or SUDI associated with different infant sleeping positions. Knowledge of the effect of sleep position on the risk of SUDI has been acquired in phases. Awareness that the prone position was dangerous has been over $90 \%$ since 1992, and awareness that the supine position is associated with the lowest risk of SIDS rose between 2000 and 2010 from about $50 \%$ to almost $80 \%$. Recent studies, however, show that the supine position is much better than either the prone or the lateral position, and there is still some way to go to raise awareness of this. Evidence in favour of the supine position has continued to accumulate, and the latest evidence suggests that SIDS risks from the lateral and the prone positions are similar. ${ }^{1012} 1319$

Most recommended interventions to reduce the risk of SUDI, notably that concerning the sleep position, are to be implemented in the home (Task Force on SIDS, 2011). Parents therefore need access to the best and most up to date information. Nowadays it cannot be expected that they would try to gather it through only one source. On the contrary, they might look for this information through several sources (eg, friends, books, the internet, etc). However, the healthcare professionals they deal with are still likely to be one of their main sources of information (if not the main source). Thus, once the media awareness-raising action associated with most BTS campaigns ended, healthcare professionals' role becomes crucial. Specifically, the findings presented in table 2 seem to suggest that there is a stronger need for more education on safe sleep for non-paediatricians rather than for paediatricians.

The percentage of healthcare professionals aware that any non-prone position would be better than the prone position has been decreasing over the past 20 years, which may reflect changes in knowledge of the relative risks of the prone and lateral positions due to recent research. The percentage of healthcare professionals recommending parents of newborns' to use the supine sleeping position alone, or, at least, a non-prone sleeping position, has been increasing. We suggest that this should represent the focus of future studies or public health policy on this topic, as such advice is, in the end, what will influence parents' choice in putting their babies to sleep. The percentage of healthcare professionals recommending the supine position exclusively seems to be around $80 \%$. Further efforts are needed to increase it in order to reduce the risk of sleep-related infant deaths among the population, especially considering the opposition to the supine recommendation that still exists both among healthcare professionals and parents. ${ }^{57}$

Further effort is needed to understand the relationship between healthcare professionals' awareness of the risks of different sleeping positions and their decisions to recommend certain sleeping positions over others. Moreover, it is important to gather more recent data from the USA, in order to develop a better understanding on how the trend has evolved in the past few years. This might also offer useful insights in order to provide more effective healthcare professional education and advice to parents aimed at reducing the risk of sleep-related infant deaths.

Contributors FdL conceived the paper. FdL and $\mathrm{AH}$ contributed equally to the acquisition, analysis and interpretation of data. FdL and $\mathrm{AH}$ contributed equally to drafting the article and revising it critically for important intellectual content, and approving the version to be published.

Funding FdL's contribution to this research was funded by the UK Economic and Social Research Council grant number ES/1026193/1.

Competing interests None declared.

Provenance and peer review Not commissioned; externally peer reviewed.

Data sharing statement As this paper represent a systematic review, all data used in it is already in the public domain.

Open Access This is an Open Access article distributed in accordance with the Creative Commons Attribution Non Commercial (CC BY-NC 4.0) license, which permits others to distribute, remix, adapt, build upon this work noncommercially, and license their derivative works on different terms, provided the original work is properly cited and the use is non-commercial. See: http:// creativecommons.org/licenses/by-nc/4.0/

\section{REFERENCES}

1. Causes of death; main primary causes of death, sex, age. Centraal Bureau voor de Statistiek website. http://statline.cbs.nl/statweb/ (accessed 10 Nov 2015). 
2. Mathews TJ, MacDorman MF, Thoma ME. Infant mortality statistics from the 2013 period linked birth/infant death data set. Natl Vital Stat Rep 2015;64:1-30.

3. Loughrey CM, Preece MA, Green A. Sudden unexpected death in infancy (SUDI). J Clin Pathol 2005;58:20-1.

4. Krous HF, Beckwith JB, Byard RW, et al. Sudden infant death syndrome and unclassified sudden infant deaths: a definitional and diagnostic approach. Pediatrics 2004;114:234-8.

5. Moon RY, Horne RS, Hauck FR. Sudden infant death syndrome. Lancet 2007;370:1578-87.

6. Mitchell EA, Krous HF. Sudden unexpected death in infancy: a historical perspective. J Paediatr Child Health 2015;51:108-12.

7. Salm Ward TC, Balfour GM. Infant safe sleep interventions 1990-2015: a review. J Community Health 2016;41:180-96.

8. Carpenter RG, Irgens LM, Blair PS, et al. Sudden unexplained infant death in 20 regions in Europe: case control study. Lancet 2004;363:185-91.

9. Hauck FR, Herman SM, Donovan M, et al. Sleep environment and the risk of sudden infant death syndrome in an urban population: the Chicago Infant Mortality Study. Pediatrics 2003;111:1207-14.

10. Li DK, Petitti DB, Willinger M, et al. Infant sleeping position and the risk of sudden infant death syndrome in California, 1997-2000. Am J Epidemiol 2003;157:446-55.

11. Blair PS, Fleming PJ, Smith IJ, et al. Babies sleeping with parents: case-control study of factors influencing the risk of the sudden infant death syndrome. CESDI SUDI Research Group. BMJ 1999;319:1457-62.

12. Fleming PJ, Blair PS, Bacon C, et al. Environment of infants during sleep and risk of the sudden infant death syndrome: results of 19935 case-control study for confidential inquiry into stillbirths and deaths in infancy. Confidential enquiry into stillbirths and deaths regional coordinators and researchers. BMJ 1996;313:191-5

13. Mitchell EA, Tuohy PG, Brunt JM, et al. Risk factors for sudden infant death syndrome following the prevention campaign in New Zealand: a prospective study. Pediatrics 1997;100:835-40.

14. Davies DP. Cot death in Hong Kong: a rare problem? Lancet 1985;326:1346-9.

15. Kattwinkel J, Brooks J, Myerberg D. American Academy of Pediatrics AAP Task Force on infant positioning and SIDS: positioning and SIDS. Pediatrics 1992;89:1120-6.

16. Orenstein SR, Whitington PF. Positioning for prevention of infant gastroesophageal reflux. J Pediatr 1983;103:534-7.

17. Guntheroth WG, Spiers PS. Sleeping prone and the risk of sudden infant death syndrome. JAMA 1992;267:2359-62.

18. Kattwinkel J, Hauck FR, Keenan ME, et al. The changing concept of sudden infant death syndrome: diagnostic coding shifts, controversies regarding the sleeping environment, and new variables to consider in reducing risk. Pediatrics 2005;116:1245-55.

19. Moon RY, Task Force on Sudden Infant Death Syndrome. SIDS and other sleep-related infant deaths: expansion of recommendations for a safe infant sleeping environment. Pediatrics 2011;128:1030-9.

20. Scheidt PC, Willinger M, Hoffman $\mathrm{HJ}$, et al. Recommended infant sleep positions for reduction of SIDS risk. Am J Dis Child 1993:147:462.

21. Delzell JE Jr, Phillips RL Jr, Schnitzer PG, et al. Sleeping position change in practice, advice, and opinion in the newborn nursery. $J$ Fam Pract 2001:50:448.

22. Hudak BB, O'Donnell J, Mazyrka N. Infant sleep position: pediatricians' advice to parents. Pediatrics 1995;95:55-8

23. Spieker MR, Brannen SJ. Supine infant sleep: what do family physicians recommend? J Am Board Fam Pract 1996;9:319-23.

24. Morgan SK, Johnson CM. Infant Sleep: resident recommendations and socioeconomic status differences in patient practices. Fam Med 2001;33:614-20.

25. Peeke K, Hershberger CM, Kuehn D, et al. Infant sleep position. Nursing practice and knowledge. MCN Am J Matern Child Nurs 1999;24:301-4.

26. Ottolini MC, Davis BE, Patel K, et al. Prone infant sleeping despite the "Back to Sleep" campaign. Arch Pediatr Adolesc Med 1999;153:512-17.

27. Hein HA, Pettit SF. Back to Sleep: good advice for parents but not for hospitals? Pediatrics 2001;107:537-9.

28. Moon RY, Gingras JL, Erwin R. Physician beliefs and practices regarding SIDS and SIDS risk reduction. Clin Pediatr (Phila) 2002;41:391-5.

29. Bullock LF, Mickey K, Green J, et al. Are nurses acting as role models for the prevention of SIDS? MCN Am J Matern Child Nurs 2004;29:172-7.

30. Stastny PF, Ichinose TY, Thayer SD, et al. Infant sleep positioning by nursery staff and mothers in newborn hospital nurseries. Nurs Res 2004;53:122-9.

31. Eron NB, Dygert KM, Squillace $C$, et al. The physician's role in reducing SIDS. Health Promot Pract 2011;12:370-8.
32. Aris C, Stevens TP, Lemura C, et al. NICU nurses' knowledge and discharge teaching related to infant sleep position and risk of SIDS. Adv Neonatal Care 2006;6:281-94.

33. Price SK, Hillman L, Gardner $\mathrm{P}$, et al. Changing hospital newborn nursery practice: results from a statewide "Back to Sleep" nurses training program. Matern Child Health J 2008;12:363-71.

34. Shaefer SJ, Herman SE, Frank SJ, et al. Translating infant safe sleep evidence into nursing practice. J Obstet Gynecol Neonatal Nurs 2010;39:618-26.

35. Moon RY, Kington M, Oden R, et al. Physician recommendations regarding SIDS risk reduction: a national survey of pediatricians and family physicians. Clin Pediatr (Phila) 2007;46:791-800.

36. Grazel R, Phalen AG, Polomano RC. Implementation of the American Academy of Pediatrics recommendations to reduce sudden infant death syndrome risk in neonatal intensive care units: an evaluation of nursing knowledge and practice. Adv Neonatal Care 2010;10:332-42.

37. Young J, O'Rourke P. Improving attitudes and practice relating to sudden infant death syndrome and the Reduce the Risk messages. The effectiveness of an educational intervention in a group of nurses and midwives. Neonatal, Paediatric and Child Health Nursing 2003;6:4-14.

38. Young J, Schluter P. SIDS: What do nurses and midwives know about reducing the risk? Neonatal, Paediatric and Child Health Nursing 2002;5:18-25.

39. Young J, Schluter P, Francis D. Final Report: nursing knowledge, attitudes and practice relating to SIDS risk factors and Reduce the Risk of SIDS messages 2002. Brisbane: Royal Children's Hospital \& Health Service District, Queensland Health, 2002.

40. Young J, New K, Colditz P, et al. Impacting nursing and midwifery knowledge, attitudes and practices relating to Sudden Unexpected Deaths in Infancy: effectiveness of a peer intervention program. Final Report. Brisbane: Royal Children's Hospital \& Health Service District, Queensland Health, 2010.

41. Yikilkan $\mathrm{H}$, Ünalan PC, Cakir $\mathrm{E}$, et al. Sudden infant death syndrome: how much mothers and health professionals know. Pediatr Int 2011;53:24-8.

42. Boccuzzo G, de Luca F. Sudden infant death syndrome: knowledge of its risk factors among Italian healthcare professionals. Electron J Appl Stat Anal 2012;5:374-80.

43. de Luca F, Boccuzzo G. [Article first published online on 12 December 2012]) What do healthcare workers know about Sudden Infant Death Syndrome? The case of the Italian Campaign Genitor Più. Journal of the Royal Statistical Society Series A: Statistics in Society 2014;177:63-82.

44. Camarasa Piquer F. Evolución del síndrome de la muerte súbita del lactante en los países desarrollados. Situación actual en España. In: Camarasa Piquer F, ed. Libro Blanco de la Muerte Súbita del Lactante (SMSL). 2nd edn. Madrid: Ediciones Ergon, 2003:1-14.

45. International Infant Mortality Statistics. International Society for the Study and Prevention of Perinatal and Infant Death (ISPID) website. http://www.ispid.org/ (accessed 10 Nov 2015).

46. Australian Bureau of Statistics. 3303.0-causes of death, Australia 2013. Canberra: Australian Bureau of Statistics, 2015.

47. Table 102-0562 Leading causes of death, infants, by sex, Canada, annual. Statistics Canada CANSIM (database) website. http://www. statcan.gc.ca/ (accessed 9 Nov 2015)

48. Causes de mortalité. Centre d'épidémiologie sur les causes médicales de décès (CépiDc) website. http://www.cepidc.inserm.fr/ site4/ (accessed 9 Nov 2015).

49. Causes of death. Statistisches Bundesamt (DESTATIS) website. https://www.destatis.de/ (accessed 9 Nov 2015).

50. Campagna GenitoriPiù. 7 azioni per la vita del tuo bambino. (Speri L, Brunelli M, eds). Roma: Ministero della Salute e delle Politiche Sociali, 2009.

51. Vital statistics. Ministry of Health, Labour and Welfare website. http:// www.mhlw.go.jp/english/ (accessed 10 Nov 2015).

52. Infant death and mortality. KOrean Statistical Information Service statistical database. http://kosis.kr (accessed 10 Nov 2015).

53. Cardesa García JJ, Galán Gómez E, Hernández Rastrollo R, et al. Epidemiología del síndrome de muerte súbita del lactante (SMSL). In: Camarasa Piquer F, ed. Libro Blanco de la Muerte Súbita del Lactante (SMSL). 2nd edn. Madrid: Ediciones Ergon, 2003:34-45.

54. Southall DP, Samuels MP. Reducing risks in the sudden infant death syndrome. BMJ 1992;304:265-6.

55. Causes of death. Eurostat website. http://ec.europa.eu/eurostat (accessed 11 Nov 2015)

56. Raydo LJ, Reu-Donlon CM. Putting babies 'back to sleep': can we do better? Neonatal Netw 2005;24:9-16.

57. Patton C, Stiltner D, Wright KB, et al. Do nurses provide a safe sleep environment for infants in the hospital setting? An integrative review. Adv Neonatal Care 2015;15:8-22. 